\title{
The future of technology and education: Where are we heading?
}

A report of a video-conferenced keynote address

\author{
Margaret Riel
}

Center for Collaborative Research in Education, University of California, 2001 Berekely Place, Irvine, CA 92697.mriel@uci.edu

Key words: future, history, technology, technology, integration, communication

Abstract: Technology is shared minds made visible. It connects people through time and across distances. Our shared past is divided into five periods which are based on the intellectual puzzles that have dominated our collective minds in terms of communication. These puzzles are discussed by focusing on how they have been transformed by technology in the past and will continue to be transformed by technology in the future. The 21 st Century will be the Age of Communities because of the rapid expansion of what is possible in terms of shared values, goals and actions by people who can communicate over time and distances in ways not previously conceived. The four C's for the future of education are: Community, Collaboration, Curriculum, and Creativity. Each of these is used to organise a discussion of where we are heading in education during the Age of Communities.

\section{INTRODUCTION}

The question that I pose today is: The future of technology and education - Where are we heading? I have used the verb 'to head' on purpose. A soundbite summary of my talk is 'technology is shared minds made visible'. I pair this with a quote from the, the walls at UCLA's Royce Hall that I believe is from the philosopher, Royce. 'Education is learning to use the tools which the human race has found indispensable'. With the current attention on $\mathrm{Y} 2 \mathrm{~K}$ problems and fears that our world may stop functioning if the computers are confused over the date, it should be clear technology is

\footnotetext{
The original version of this chapter was revised: The copyright line was incorrect. This has been corrected. The Erratum to this chapter is available at DOI: 10.1007/978-0-387-35499-6_29 
essential to our society. The important question is not if we should use computers, but how we should be using this technology.

All technology is shared minds made visible but I will focus on the technology that enables sharing knowledge across distances and across time. Across time we need to save our wisdom so that we can compare the past to the present, make predictions and adapt our behaviour to the next cycle, to establish and protect rights and responsibilities, as well as to solve puzzles, celebrate successes and inspire new ideas. Now we also want to share across distances, to extend the range of our communication. We communicate across time to co-ordinate behaviour, to provide for group needs, to announce events or share information or observations, and to warn others when we are in harm's way. I will show you technologies that we have evolved for communicating across time and distances.

\section{HISTORY OF INFORMATION TECHNOLOGIES}

One way of lookinmg forward is to look behind us at where we have come from. I will show five periods of time characterised by different technologies for making our shared minds visible. I will discuss:

- Pictorial representation in the Age of Pictographs

- Representations of speech in the Age of Alphabets

- Access to literacy in the Age of Print

- Multi-sensory Recording in the Age of Graphics

- Multi sensory interaction in the Age of Communication

- And the future which I am calling - The Age of Communities.

\subsection{The Age of Pictographs}

We begin with pictorial representations in the earliest time, the Age of Pictographs (Figure 1). Early humans wrote on cave walls saving important information across time. For more portable messages, they carved and drew on bones and later on their portable cave walls - clay tablets. In $2500 \mathrm{BC}$ we appears the first form of paper, papyrus.

Early humans communicated across distances by shouting and whistling. They made flutes which could have been used as signals as well as for music; they could have used drums and signals from fire, torches, and smoke. By $2000 \mathrm{BC}$ the domestication of horses and the invention of the wheel made it possible to send messages across greater distances at faster speeds. So we have always put information in public spaces from cave walls, palace walls, church walls, billboards to neon signs. Jim Sphorer and Sonny Kirkley are currently working on an Internet markup language to take the web out of the box and place it in the world. They will attach websites to a specific latitude, longitude and altitude. Information could also be attached 
to objects and people through the use of bar codes, radio frequency tags or small transmitters embedded in objects. Then using portable wearable devices such as watches, palmpilots, glasses, or headgear people can experience information tied to places.

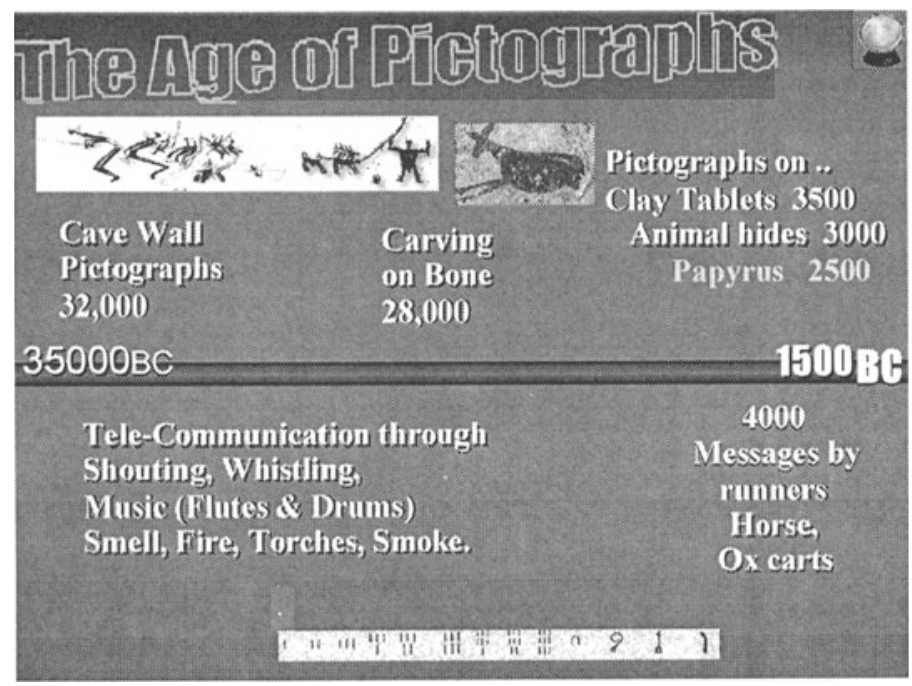

Figure 1. The Age of Pictographs

An example is a bike rider with a key pad that enables him to project virtual road signs computed for his purposes. These virtual signposts can tell him how far he has travelled, his speed, the time, and when to turn left, as well as other useful information about his journey. Instead of finding the route information on the Internet, printing it and trying to read a map folded over the handlebars, the rider sees the map superimposed on the pavement indicating when a right or left turn is needed to reach the specific destination. The rider can use the keypad to call up information about weather, hotels, restaurants or attractions. The information appears on virtual road signs only visible when they are needed. The rest of the time the rider can enjoy natural sights without the clutter of road signs.

In Museums, digital guide devices will allow for flexible use. You could programme a special tour around your interests and the time available and follow the purple footsteps that suddenly appear on the ground, or you can wander. Objects can have radio tags so at an exhibit you can see information about it in the language you select. Transparent markers temporarily appear to help guide you. Any one exhibit can be linked to infinite information on the Web so the choice of how much to learn will be a visitor decision, not one determined by exhibit designers. 
Students going on field trips could explore more freely as they will be in less danger of becoming lost. Small devices will report their location and provide regular contact with the teacher. Information about an object, animal, plant, place, or process will not need a person to stand by the group and explain over the sounds that children make. Students could access the information and search for answers to their particular questions. They can collect information or measurements at a location. Graphs could show the results in real time as they collect it. The information that each child brings back from the field trip will not be identical and increase the value of having students work together; for more information consult Worldboards (www.worldboards.org).

\subsection{The Age of Alphabets}

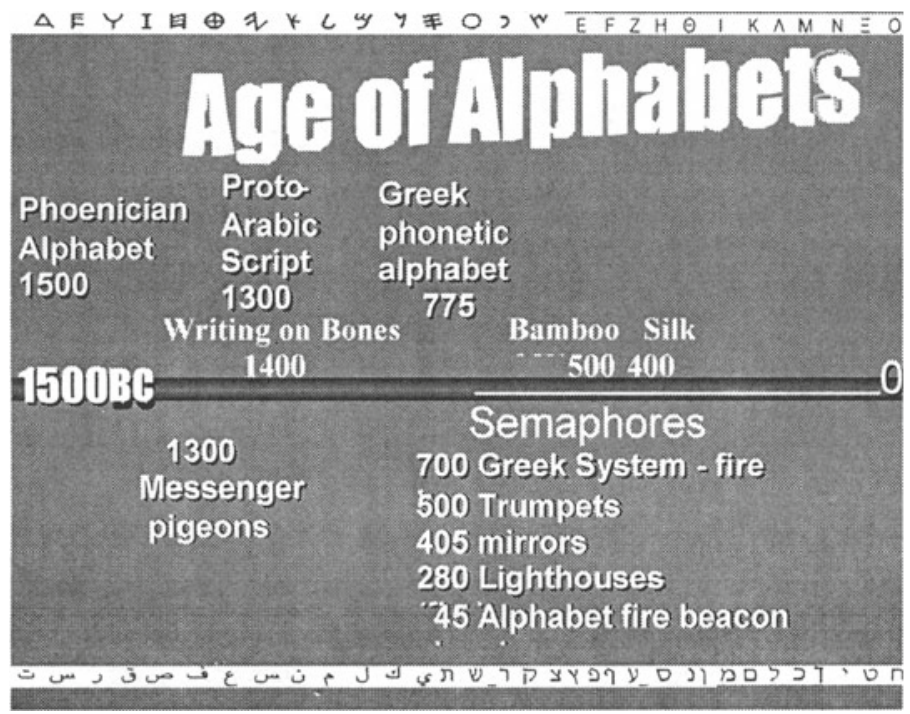

Figure 2. The Age of Alphabets

The Age of Alphabets was dominated by the task of inventing ways of coding our spoken language into a written language; in this period eight different scripts for coding language were created. In Figure 2 I have listed a number of different kinds of signal systems, or semaphores. In $45 \mathrm{BC}$ there is evidence of using the fire signals combined with a code to transmit verbal messages. The alphabet letters were divided into five groups of five. A system of sending fire signals was devised that involved sending two numbers for each letter (one for the group and one for the position in the group). This was the telegraph system; see Figure 4. If we fast forward, how 
are we continuing to solve the problem of saving our ideas in text over time? Of course, the printing press, the typewriter and the computer are part of this story. The QWERTY typewriter is not one of our most efficient tools; but all keyboards may soon find themselves on closet shelves. We are very close to talking instead of typing with our computers.

Increasingly we will have devices that will allow us to project images, hear speech and interpret our words. When we approach our house or car, our voice will operate like a fingerprint unlocking the door. We will have smart appliances that respond to verbal commands. As one gives a talk, the written record will be recorded in text making it possible for us to really listen, watch and worry less about taking notes. Linguistic barriers may not divide us as strongly as they do today. While translation programmes today are still far from adequate, they do project an image of the way in which we might move flexibly across languages.

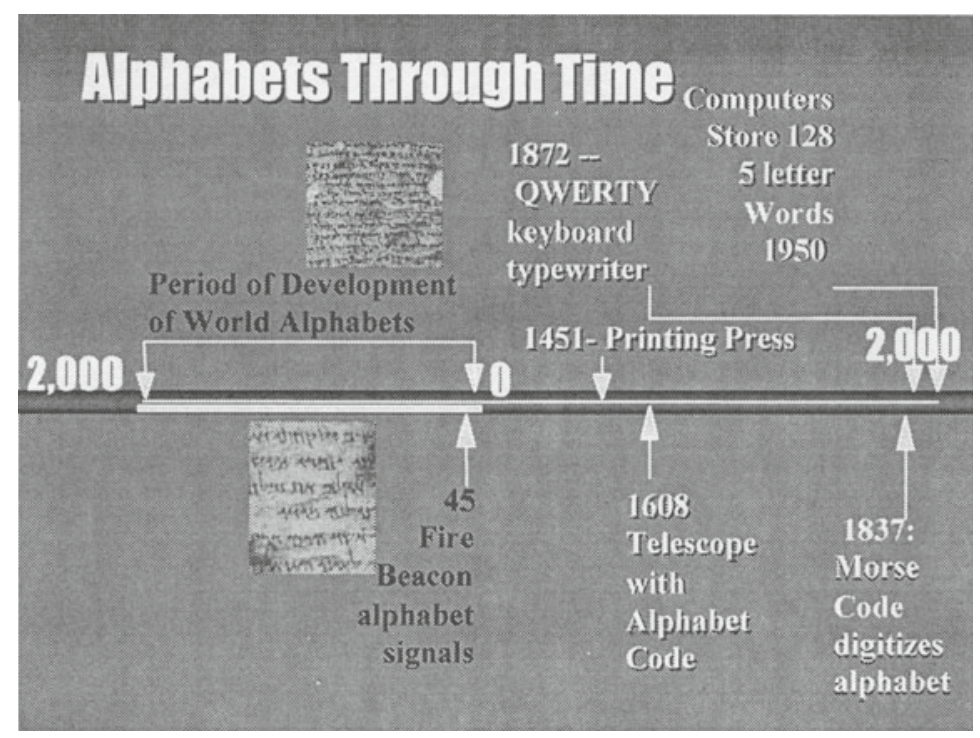

Figure 3. Alphabets through time

Here are a few scenes from a video created by a team of visionaries from AT\&T Bell Labs (now Lucent Technologies), called Connections. Note there are no keyboards, all the machines are interactive, with personal agents that keep track of work. The use of the picture window as a computer screen is similar to the conception of Worldboards that I discussed earlier - the ability to project information anywhere. 


\subsection{The Age of Print}

In the Age of Print the invention that dominated was the printing press. It was the time that we also figured out how to make the paper necessary for the printing press. At the beginning of this period, quills were used for writing. In 1565 we invented pencils, and later steel point pens. If we look below the timeline in Figure 4, we see that we are continuing to find ways to extend our ability to communicate over distances. Calling post messengers was a sequence of people positioned shouting distance apart. One person would shout the message to the next who would shout it to the next; they could get a message 153 miles from sunrise to sunset by this means. This led to ideas about how to use vision with using various signals which included flags.

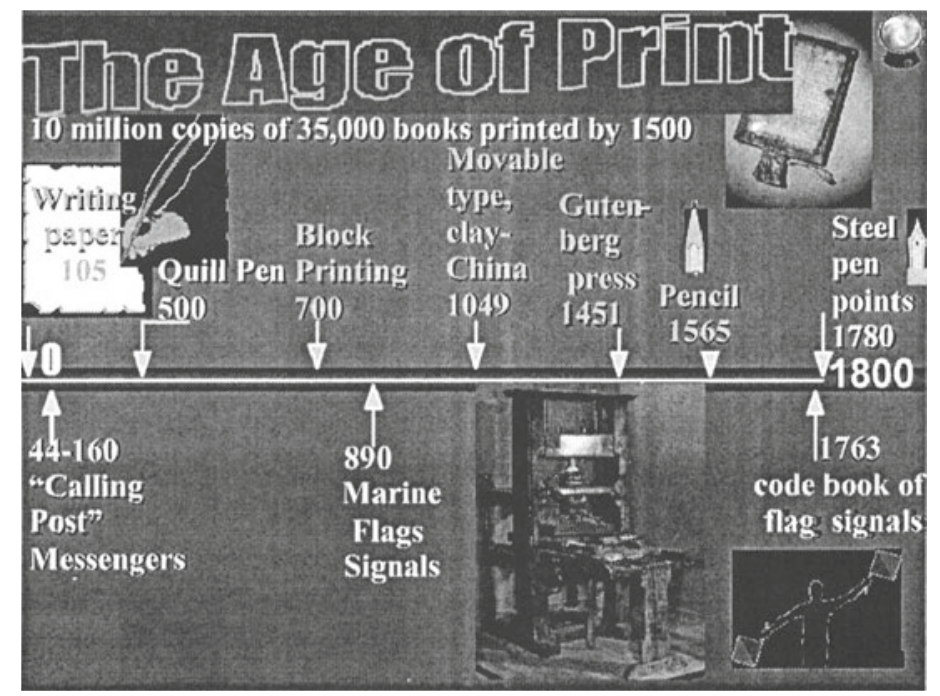

Figure 4. The Age of Print

Let us consider the pencil (Figure 5). It took 300 years to create the modern pencil with an attached eraser. I don't know why that is. I wonder if we were so excited about being able to write things down, that the idea of erasing them was not a high priority. But with the eraser came the ability to write, erase and rewrite. Current cutting edge technology is electronic paper for printing books that we can erase as easily as marks from a pencil. The printing press let us create thousands of copies of the same book as easily as we created a single copy in the past. But we have not before thought about unprinting a book.

Below is an extract from an article by Bennett Davis, to help you think about what digital paper might look like. Not a screen - at Xerox and MIT, 
scientists are designing digital paper with the look and feel of paper and ink - as thin, flexible, portable and crisply readable as paper:

Stack these electronic pages together, flick a switch and you can have any book you want: Hamlet, the latest John Grisham or the proceedings from the conference you attended last week. As with any other book, the print and pictures will remain in place for years without drawing electrical power. The one big difference is that when you want something else to read, the old text vanishes and the new replaces it. From newspapers and magazines to fax machines and advertising hoardings, the possibilities for electronic paper are endless. Already, posters made from electronic paper are hanging in a store near Boston. Within a couple of years, the inventors expect, they will have spread to supermarkets, airports and other public places. By 2006, the researchers predict that they will have mastered the subtleties of colour, and electronic paper will begin to replace the displays on pagers, machinery, calculators, digital clocks and even computer screens. Twenty years from now your groaning bookshelves could be replaced by a single electronic book.

http://newscientist.com/ns/19990515/papergoese.html

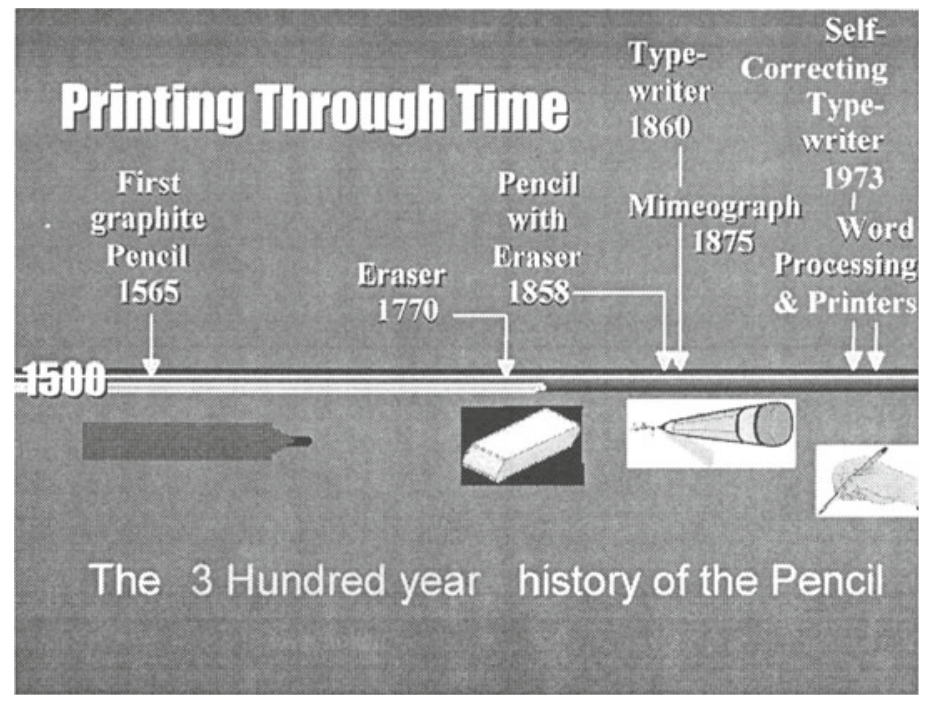

Figure 5. The 300 year history of the pencil

The quality of print on electronic paper is similar to the output of laser printers, and does not lessen over time. An average 250-page novel takes up 1 megabyte of storage space, so with existing technology 100 books could 
be squeezed into tiny chips embedded in an electronic book's spine. Some new technology for storing information will make it possible for a digital book to change into thousands of different books. E-Ink's electronic paper can change the image on a page as often as 20 times a second. Digital paper will be used in signs, books, cards, and newspapers. In this last case, we will no longer need to recycle huge piles of newspapers. Your 'news-paper' will stay wherever you like to read it. It will be reprinting all the time so that when you pick it up to read it, it will be current. The change will be analogous to that of the evening news to $\mathrm{CNN}$ on television. Stories may be similar over a short period, changing when the news changes. So as an event unfolds, the story will be updated as the reporter sends in new information. Either linked by phone lines or radio transmissions, your 'news-paper' will let you read the most current news at any time.

I highlighted the pencil of the last period for another reason. This writing 'lead' was given its current name Graphite at the end of the 18th century. This word graphien from the Greek to write or draw, serves as a metaphor for this next century of inventions. Notice the ending of most of the inventions of this time period. They end in this same stem-graphic or graphy - the lithograph, the photograph, the mimeograph, (school printing press), kinematograph, the radiograph, the telegraph. Why are they so named? I think because we wanted to write down, to record our multi-sensory experiences. We had already found ways to represent what was said in print; the typewriter is part of the progress of the Age of Print. But now we recorded exactly what our eyes saw and what our ears heard. At first these recordings were separate and static. But they enabled us to save what was seen and heard; to view or listen to sights and sounds as we please tomorrow, next month or in years to come. On the bottom half of Figure 6, is the telegraph, the transition technology to the communication age. How have we moved forward in our ability to record our experiences?

If we fast forward from the 19th century our ability to save and store sensory information increases in capacity while getting smaller in size. An article on IBM by John Markoff about magnetic storage capacity, describes how 100 books could be embedded in an electronic book's spine or covers. In a few years, with only the weight of single book, our students will be able to carry whole school libraries, in readable form, in their backpack in a book weighing far less then an average textbook of today. You could highlight text, underline or add code words and the content saved in your personal database with reference of the source and links to the original article. Now that is connected information! 


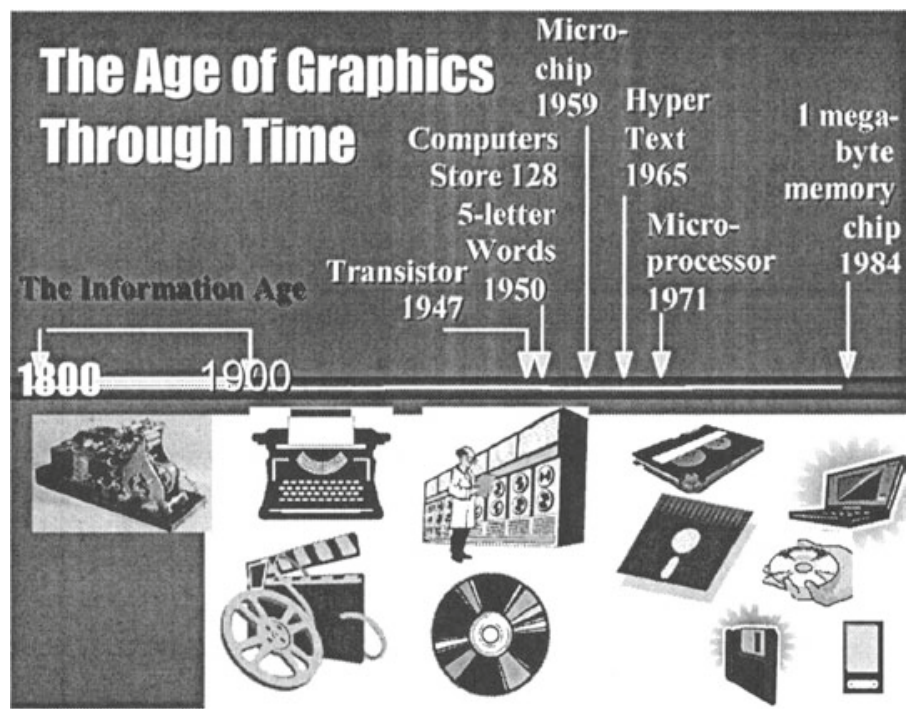

Figure 6. The Age of Graphics through time

\subsection{The Age of Communication}

Finally, we arrive at the Age of Communication (Figure 7). One point is that it becomes more difficult to decide what to put above or below the line. Most technologies for communication through time can also be used across distances. Is television about transmitting information live across distances or making entertainment to last? With digital communication, information can be transmitted, saved and recorded. It makes no sense to ask if a computer is a storage or communication device. I call the last century the Age of Communication rather than the Information Age because it is not just about new ways to store information, a task that continues from the past. The imagination of this century was focussed on communication and connections over distances. I would point out the use of the prefix 'tele' just as I highlighted the suffix 'graphic' in the previous century. The telegraph is the transition technology from the 19th century as it contains both the prefix and suffix. It is followed by the television, telephone, telerobotics, and teletype; we talk about activities such as tele-teaching and tele-mentoring in telecourses, and tele-conferencing, and tele-marketing in telecommunities. Another common stem is 'cyber' as in cybernetics or cybercafes, a reference to the helmsman again emphasising finding our way across the distance.

Intel, the company that developed the microchip that made personal computers possible, did not build a personal computer. Gordon Moore, cofounder of Intel, reports that the idea was discussed but they could not think 
of any use for a personal computer in the home. The only use the designer could imagine was having his wife store recipes on it! Without a vision of what it would be used for, they did not build it. (PBS, Triumph of the Nerds, http://www. pbs.org/nerds/transcript.html). The first personal computer was an Altair 8800, the idea of an ex-airforce officer, Ed Roberts, who conceived of this kit to keep his calculator company from collapsing. The Altair did little; it was a box with switches as input devices and lights as output. You had to build it yourself and many did not work. But it inspired Steve Wozniak to build the Apple 1 computer kit. This was little more of a computer than the Altair, a single circuit board with neither case nor keyboard. Still, Steve Jobs sold 50. That indicated there was a market for personal computers; the Apple II appeared 2 years later with a monitor and keyboard and printer giving rise to a new industry.

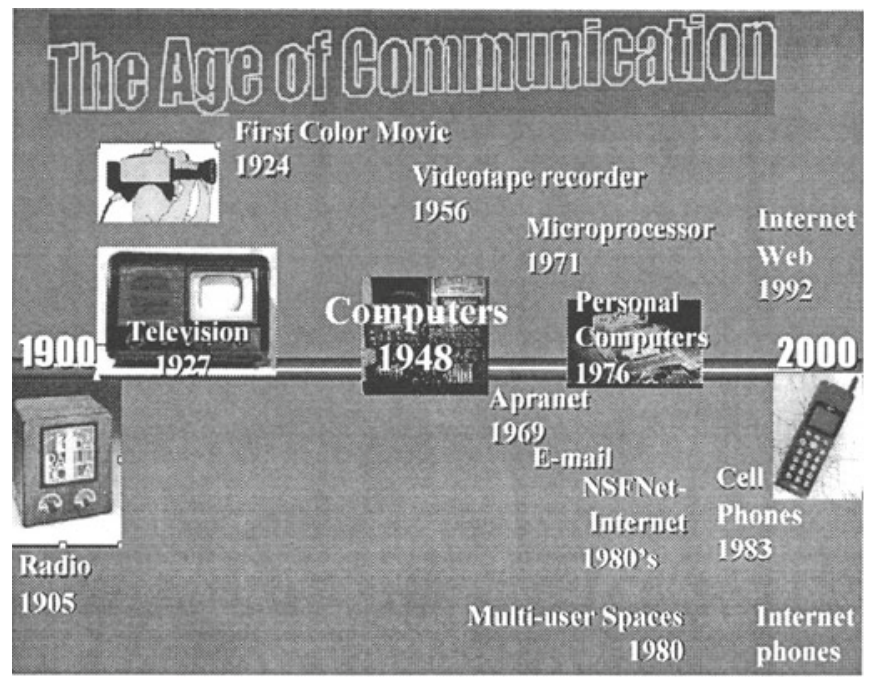

Figure 7. The Age of Communication

At the same time, Vint Cerf was considering an Internet protocol to make it possible for computers to exchange information and share processing power. This insight lead to the development of a world-wide Internet. To understand how we will be moving forward with each of these developments, we need only to look at the plans for Internet II, the teleimmersion project at Advanced Network and Services (http://www.advanced.org/). 


\subsection{The Age of Communities}

In the 21 st century we will be able to access, project and store information wherever we go without having to go to the computer. We will have devices that can project the information we need using the world as a screen (Figure 8). We will be able to talk to our tools using natural language to facilitate many of the things that require manual inputs now. Working across languages will become easier as the need to becomes more critical. The book we carry with us will display libraries of information at our fingertips without wires. We will be connected to whomever we want and we will be able to leave computer agents to take care of the interactions that we cannot handle. Physically we will be in one location but we will have the sense of being in multiple spaces mentally. We will share these informational spaces with others who are working on similar goals and interests.

The communities we form will be virtual and they will be the way we come to see ourselves and others, contributing to our identity. We identify ourselves by our name, occupation, generation, geographic location, nation, nationality and perhaps religion. In the future we may also include where we homestead on the net. Finally incorporating all of these inventions for sharing minds, the students at the University of California, Santa Cruz have created a glimpse of what learning environments on the web will soon look like. This extract is drawn from a shared Active World environment, Touring Virtual University of California, Santa Cruz that students have created working with Bonnie DeVarco. This active world construction is being developed as a different way of creating online educational and social contexts.

Welcome to the virtual UCSC campus, a 21st century university. Hi, I'm Anna and I'm a fine art major for the college, I'll be your virtual guide for the next few minutes. This is not really me of course, this is my avatar, my persona in cyberspace. I'm sitting in front of my computer but with my avatar I can take you on a virtual tour of our campus. Just kick back in front of your screen and I'll show you the ropes...We just warped over to the campus teleport map. UCSC students built this campus, I think that's pretty cool. And they did it as a summer project with world class 3-D designers, living in other countries. Many of our team members haven't even met each other in person but it doesn't really matter. Why not? Because our campus is a shared virtual space. We can all meet here but be physically located anywhere on the planet. 


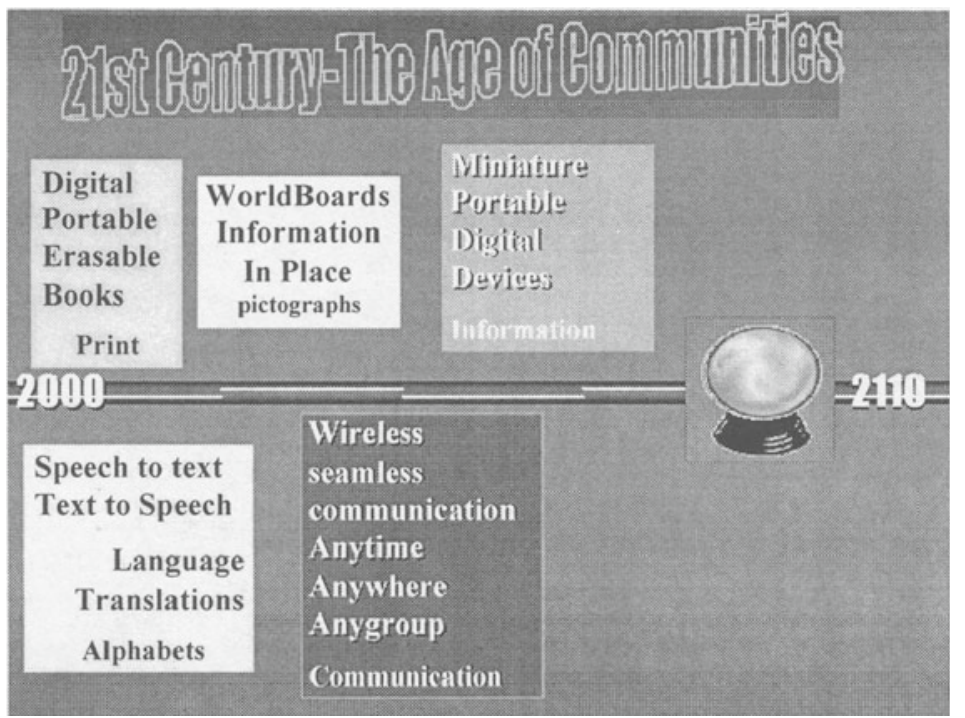

Figure 8. The 21 st century: The Age of Communities

For more information see Avatar 98 Virtual Education (http://www.cruzio.com/ devarco/av98edu.htm). For examples of new technologies and images of the future, explore - Learning Spaces in the Networlds of Tomorrow (2http://www.iearn.org/webtour/2).

\section{THE FUTURE}

If I am right about the next century, education as well as work will be much more collaborative. I want to consider a business card from a new organisation - the Center for Innovative Learning Technologies. Notice this business card has a hole in the middle; if you flip it over you see that it is a circle with a square in it. This card has 13 megabytes of information stored on it and will play in any CD-ROM machine. The message is from CILT, a collaboration of research centres from across the US, who are exploring ways in which technology is changing teaching and learning. They are organised into research themes and encourage a new level of partnership that may lead to important research findings. In the introduction of their business card are quotes form a number of people making predictions about the future. Examples include: I foresee an analytical machine that can not only foresee, but can act on that foresight (Charles Baggage, Envisioned the computer, 1834); I foresee that the analytic machine might compose music and graphics of any degree of complexity or extent (Lady Ada Bryon Lovelace, Wrote the first computer program, 1843); I foresee a world market for maybe 5 computers. (Thomas Watson, Chairman of IBM, 1943); I 
foresee a time when computers may weigh no more than one and a half tons. (Popular Mechanics, 1949); and I foresee no reason for people to have a computer in their home (Ken Olson, President, Digital Equipment Corporation, 1977).

So it is not always easy to guess where we are heading. Where are we heading? Can I foresee the future? I know I can 4-C the future, using Community, Collaboration, Curriculum, and Creativity.

\subsection{Community}

The Center for Innovative Learning Technology (www.cilt.org) (US) and the TeleLearning Centre of Excellence (www.telelearn.ca) (CA) are research communities that believe that community research efforts are more powerful than individual ones. Researchers work together with their unique perspectives and different populations to create better understanding of common results. With the changes in education involving working worldwide, it does not make sense to work alone any more. Institutions providing professional development to teachers are working in larger coalitions (explore the Tapped In community (tappedin.sri.com)). Here teachers and support agencies from across the United States come together in a social online environment for teacher professional development. At the school level, world-wide communities are helping students work with their peers around the world in problems they share. A good example is the International Education and Resource Network (www.iearn.org).

\subsection{Collaboration}

Here is a list of groups to illustrate the level of collaboration that I see happening in the near and distant future:

- Virtual Canyon (www.virtual-canyon.org)

- ThinkQuest org (www.thinkquest.net)

- IEARN Learning Circles \& Projects (www.iearn.org/projects)

- Passport to Knowledge (passport.ivv.nasa.gov)

- Knowledge Forum (learn.motion.com/lim/kf/KF1.html)

- Globe (www.globe.gov)

- Virtual High School -Concord (concord.org)

- The George Lucas Education Foundation (www.glef.org)

The Virtual Canyon Project, Monterey Bay, (www.virtual-canyon.org) shows you what this collaboration will mean for teaching and learning. Using a web site to explore Monterey Bay on the research institute's boat, students pose and test questions in a proper investigative fashion. One student then commented: 
I've always wanted to work with the scientists because I really admire them and really look up to them with all of their work that they've put into it and just being with them it makes me feel like you know, that I'm part of this and not just some little kid that they're teaching ...

This is what we are working towards, for children to feel such motivation, partnership, collaboration and community around good content.

I also want to mention some research I'm doing with, Hank Becker (who is here tonight with me providing me a local audience along with Mike Miller who I want to also thank for all of this technical support). I was surprised to learn from a national survey of teachers that the number of teachers in this country who are engaged in these exciting projects is less than $10 \%$ (www.crito.uci.edu/tlc). So while we celebrate the accomplishments of the these few classrooms, we need to think about how to make it possible for more students to engage in this type of learning., We are learning from the teacher's professional role orientation, and collaborative schools culture, that the position of teachers in the educational community mirrors the position of students in the classroom community (Becker and Riel, 1999). Teachers who have been making the types of shifts that I have been describing have classrooms in which students are encouraged to play leadership roles. However this data indicates that $55 \%$ of American teachers are engaged in what we call private practice, isolated and insulated from the changes that are part of our world. They are missing the benefits of shared minds.

\subsection{Curriculum}

What we teach is important, and we are beginning to address this question world-wide in the area of mathematics and science. The Third International Math and Science Study (nces.ed.gov/timss/) is not just looking at test scores, but also looking at what is taught and how the curriculum is organised in different countries. While using performance on standardised tests might not be the best outcome measures for this form of comparison, the analysis of curriculum decisions worldwide should help us make decisions about the best content. It is important for students to learn what has come before so that they can look forward from the perspective you get standing on the shoulders of giants. What they see into the future will shape the world. Creative tension is needed between what they learn and how they use this content to see in new ways. I also want to mention the collaborative curriculum building tools that Stone Wiske at Harvard is developing (learnweb.harvard.edu/ent/). They are helping to create teacher dialogues around curriculum building. 


\subsection{Creativity}

I recommend the book: How children learn, brain, mind experience in school; read it online at (www.nap.edu/books $/ 0309065577 / \mathrm{html} /$ ). I urge you to read the chapter on the relationship of brain development to learning. The way in which the brain develops is dependent upon the form and process of shaping understandings. Very young children overbuild an extensive neural network, and this system of pathways is used to link experiences that a child encounters. Those pathways that are not used are eliminated. So the brain is shaped by the experiences that students encounter in and beyond school. This new line of research may be able to provide a strong incentive for constructivist learning which has long been one of the dominant psychological theories of learning.

I am going to end with an example to illustrate why we need to pay attention to what students are doing creatively with their minds rather than focus narrowly on conformity. I am fearful that high test performance is going to create a strong pull toward conformity and restrict a focus on creativity. Children learning the alphabet and their numbers, often reverse them. Some students have a lot of trouble with the $J$ and $\mathrm{Z}$ and the 5 and 6 . We don't ask why. We are not curious about why they reverse these letters and focus our teaching energies on getting them to form the letters correctly. But if we were to look at what kids really do and pay much more attention to how they are thinking, we would see that, there's actually something funny about the $J$ and the $Z$ and the 5 and the 6 . In fact, reversing these letters is a sign of students who are not just copying what they see but really thinking.

Look at capital letters. Ignore those that are symmetrical like the $\mathrm{O}$ and $\mathrm{H}$ and notice that all of the other letters, well all but two, orient to the right. The two of course are the $J$ and the $Z$. Now look at numbers, ignore the symmetrical ones, and you will see a different pattern. They all orient to the left with two exceptions. Now I'm not suggesting we should switch the J with the 6 or the 5 with the $Z$ to make the pattern perfect. But I am suggesting that we should look very carefully at what children are doing, because hidden in these errors is evidence of thoughtful analysis - finding a pattern and applying that pattern to new constructions. Early learning is directed by using experience to find patterns and then applying those patterns or rules to the evidence. We see this same process of rule application in the language learning of young children if we look at their errors. A child who says "he goed to the store" understands something about present and past tense and is not just repeating what was heard. Children also discover exceptions to rules but how we react to these errors may shape their future behaviour. Students that are rewarded for thinking will continue to think accepting errors as a natural process of learning. Students who are 
only rewarded for correct answers will learn to distrust thinking and focus on memorisation as the major learning tool. Memorisation will help students learn what everyone else knows and this conformity is rewarded on standardised multiple choice tests. However real thinking means taking risks. It means sometimes being wrong but understanding why and trusting your minds to create new ideas.

In the research with Hank Becker, teachers who made a shift to more constructivist teaching practices reflected on what caused the change. The most common response was changes in the way they see their students learning. And while they do not often list computers as the major reason for change, it turns out that computer use is high in the group of teachers who make this shift and focus more on student learning. This is evidence that collaboration and community supported by computers and networks will help us pay more attention to student creativity. In conclusion, the message for the future is to pay more attention to what children are doing, to help them develop their brains, develop their minds and share their minds with others. I think that the 21 st century will be about community building because we have all the tools in place and I think these are the tools that we need for the 21 st century. So I end with my beginning: Technology is shared minds made visible.

\section{BIOGRAPHY}

Margaret Riel is the Associate Director of the Center for Collaborative Research in Education, at the University of California, Irvine. She has developed and researched models of network learning, particularly crossclassroom collaboration designs. She has written a number of research reports and articles (www.crito.uci.edu). Her recent research involves helping educators pursue their own professional. Her online office is found at www.gse.uci.edu/mriel.html. 